University of Nebraska - Lincoln

DigitalCommons@University of Nebraska - Lincoln

Papers in Ornithology

Papers in the Biological Sciences

2011

Sparrows Use Multiple Status Signals in Winter Social Flocks

Alexis S. Chaine

Station d'Ecologie Expérimentale du CNRS à Moulis, France, alexis.chaine@ecoex-moulis.cnrs.fr

Kris A. Tjernell

Conservation Strategy Group LLC, Sacramento, CA

Daizaburo Shizuka

University of Nebraska-Lincoln, dshizuka2@unl.edu

Bruce E. Lyon

University of California, Santa Cruz, belyon@ucsc.edu

Follow this and additional works at: https://digitalcommons.unl.edu/biosciornithology

Chaine, Alexis S.; Tjernell, Kris A.; Shizuka, Daizaburo; and Lyon, Bruce E., "Sparrows Use Multiple Status Signals in Winter Social Flocks" (2011). Papers in Ornithology. 89.

https://digitalcommons.unl.edu/biosciornithology/89

This Article is brought to you for free and open access by the Papers in the Biological Sciences at DigitalCommons@University of Nebraska - Lincoln. It has been accepted for inclusion in Papers in Ornithology by an authorized administrator of DigitalCommons@University of Nebraska - Lincoln. 


\title{
Sparrows Use Multiple Status Signals in Winter Social Flocks
}

\author{
Alexis S. Chaine, ${ }^{1,2}$ Kris A. Tjernell, ${ }^{1,3}$ Dai Shizuka, ${ }^{1,4}$ and Bruce E. Lyon ${ }^{1}$ \\ 1. Department of Ecology and Evolutionary Biology, University of California, Santa Cruz, Santa Cruz, CA 95064, U.S.A. \\ 2. Station d'Ecologie Expérimentale du CNRS à Moulis USR2936, France \\ 3. Conservation Strategy Group, U.S.A. \\ 4. Department of Ecology and Evolution, University of Chicago, U.S.A. \\ Corresponding author - A. S. Chaine, Station d'Ecologie Expérimentale du CNRS à Moulis USR2936, 09200 Saint-Girons, France; \\ email alexis.chaine@ecoex-moulis.cnrs.fr
}

\begin{abstract}
Status signals are thought to reduce the potential costs of social conflict over resources by advertising social status to other group members and reducing unnecessary contests between individuals of differing abilities. Nearly all studies of status signals to date have focused on single signaling traits, and most studies that have investigated multiple traits did not examine whether different traits are used in different contexts, as is required for them to function as multiple signals. We examined the role of gold and black crown patches of wintering golden-crowned sparrows, Zonotrichia atricapilla, in determining social dominance during experimentally staged encounters between unfamiliar individuals. Specifically, we determined whether variation in weakly correlated or uncorrelated traits (crown patch size and color, body size) differentially affected the outcome of interactions involving avoidance versus aggression. Overall, crown patch size and color were better predictors of dominance than were body size or sex. Several traits, including both crown features and morphological traits, predicted which individual avoided the other in dyadic interactions that did not escalate beyond avoidance. However, when dyads had similar gold crown patch sizes, the interaction was more likely to escalate, leading to aggression. In contrast to avoidance interactions, the outcomes of aggressive contests were largely predicted by variation in the color of black crown patches. Taken together, our results show that gold and black crown features operate as multiple status signals that accommodate an escalated gradient of interactions and suggest that social status involves more complexity than can be accommodated by a single signal.
\end{abstract}

Keywords: carotenoid, escalated contest, golden-crowned sparrow, melanin, multiple signals, plumage, social dominance, status signal, winter flock, Zonotrichia atricapilla

Contests over limited resources are a ubiquitous feature in many species, but organisms must strike a balance between the benefits of winning a resource and the potential costs associated with competition (Geist, 1966; Rohwer, 1975). The status signaling hypothesis proposes that signals are used to indicate relative fighting ability and thereby reduce the potential costs (e.g. time, energy, injury) of fighting over resources (Rohwer, 1975, 1982; Rohwer and Ewald, 1981, Whitfield, 1987; Searcy and Nowicki, 2005). In birds, research on status signals has largely involved the color and area of distinct feather patches. Signals conveying information regarding an individual's fighting ability (Rohwer 1975) should benefit both the signaler and the receiver by minimizing costly aggressive interactions between birds of different fighting abilities (Searcy \& Nowicki 2005). Status signals have now been demonstrated in a broad variety of taxa in both breeding and nonbreeding contexts (Senar, 1999; Whiting et al., 2003; Searcy and Nowicki, 2005; Senar, 2006; Tibbetts and Safran, 2009), but have been especially studied in avian winter flocks (Rohwer, 1975, 1977, 1982;
Watt, 1986a, 1986b; Whitfield, 1987, 1988; reviewed in Senar 2006). Winter status signals are thought to be particularly important during flock formation, or when new birds join an already established flock (Rohwer, 1975, 1982).

The assumption in most studies of social dominance has been that fighting ability is a simple message that can be conveyed in just one signal. Accordingly, work on status signals has largely been restricted to analyses of a single trait (see Balph et al., 1979 \& Bókony et al., 2006 for notable exceptions). For example, a recent review of plumage-based status signals in sparrows, a group that has been particularly well studied for status signals, focused entirely on one signal, melanin-based plumage patches (Tibbetts \& Safran 2009). In striking contrast, studies of social signals used in a sexual selection context, sexual ornaments, have recently focused on animals that display multiple signaling traits and how these traits affect mate choice (Candolin 2003). Multiple signals are traits that show some phenotypic independence and convey either independent information to the same receiver or different in- 
formation to different receivers (Møller and Pomiankowski, 1993; Candolin, 2003). Although sexual selection studies of multiple signals have mainly concerned mate choice, several studies have investigated multiple signals in the context of intrasexual competition over mates using both visual and vocal traits (Ligon et al., 1990; Zucker, 1994; Pryke et al., 2002; Pryke and Andersson, 2003; Stuart-Fox et al., 2006; Chaine and Lyon, 2008; MacDougall-Shackleton et al., 2009; Sprau et al., 2010). These studies confirm that multiple signals during the breeding season are not restricted to a mate choice context; they also function in male-male competition over females or resources critical for attracting mates. These findings raise the key question as to whether multiple signals of social dominance might also apply to nonbreeding contexts, but only two studies have been conducted to date (Balph et al., 1979; Bókony et al., 2006).

In this study, we examined whether two plumage patches in golden-crowned sparrows, Zonotrichia atricapilla, serve as multiple status signals during contests in winter flocks. Golden-crowned sparrows have conspicuous crown patches that comprise a central gold patch flanked by two black stripes extending from the beak towards the back of the head (Norment et al. 1998). The black and the gold crown patches have the potential to provide different signal information because they depend on distinct developmental pathways for production. The color of black crown feathers derives from melanin deposition during feather growth, which is thought to be largely under hormonal and social control ( Jawor and Breitwisch, 2003; McGraw, 2003, 2006b). In contrast, the gold patch contains carotenoid coloration (K. A. Tjernell, B. E. Lyon, D. Shizuka, \& A. S. Chaine, unpublished data following the method of McGraw et al. 2005) which depends on the acquisition of carotenoid molecules from external food sources ( Hill and Montgomerie, 1994; McGraw, 2006a). Both plumage patches are more variable in winter than during the breeding season (B. E. Lyon, D. Shizuka, \& A. S. Chaine, unpublished data), owing to a postbreeding molt in the autumn. Such an increase in variation in winter plumage coloration is also seen in other Zonotrichia sparrows, and these plumage patches are known to facilitate social interactions ( Fugle et al., 1984; Rohwer, 1985; Watt, 1986a, 1986b). A previous study of goldencrowned sparrows provided indirect evidence that plumage affects social behavior in winter: interindividual crowding at a feeder was marginally higher for individuals with less striking crowns (Pearson 1979). However, that study was based on simple categories of crown brightness that pooled both plumage features into a composite rank measure and, moreover, spacing distance may be a poor metric of social dominance.

We evaluated the hypothesis that the distinct gold and black crown patches function as multiple signals of social dominance among unfamiliar individuals in golden-crowned sparrows. We used controlled social dominance experiments to test a key prediction of the multiple signal hypothesis: different traits should be associated with different contexts or forms of dominance. In addition, we also examined phenotypic correlations between the different plumage traits because signaling traits that show very high phenotypic correlations would not provide independent information to a receiver, contrary to a key assumption of multiple signal theory.

\section{Methods}

\section{Capture and Measurements of Birds}

We caught golden-crowned sparrows in January and February of both 2005 and 2006 using baited Potter traps at four sites located near the University of California, Santa Cruz. For each bird we took standard body size measurements immediately after capture (mass, flattened wing chord, tarsus and beak length), took a small blood sample from the ulnar vein (ca. $20 \mu \mathrm{l}$ ) for determining sex, and fitted each bird with a USFWS bird band and a unique combination of colored vinyl leg bands (Hill 1992). To quantify crown patch sizes, we took digital photographs perpendicular to the top of the head and included a size standard to scale images. We then used Adobe Photoshop to isolate and calculate the areas $\left(\mathrm{mm}^{2}\right.$, repeatability across photos of the same individual taken on the same day: black: $r_{2.1,29}=0.96 \pm 0.02$; gold: $\left.r_{2.1,29}=0.96 \pm 0.02\right)$ of the gold and black portions of each crown. We measured the colors of these crown patches with an Ocean Optics USB2000 spectrometer and a PX-2 pulsed xenon light source. The fiberoptic probe was fitted with a tip, restricting measurement to a standard $2 \mathrm{~mm}^{2}$ diameter area at a $45^{\circ}$ angle (Andersson and Prager, 2006; Chaine and Lyon, 2008). Three measurements of each of the two patch colors (gold, black) were taken for each bird and the spectrometer was standardized on both light and dark standards between measurements (three birds had missing spectrometry data).

Morphological and plumage color measures were simplified for analysis. The first principal component of the three measured body traits (factor loadings: tarsus length $=0.77$, beak length $=0.71$, wing chord $=0.67$ ) accounted for $50 \%$ of the variation in those characters, and was used as an overall measure of body size (e.g. Pryke and Andersson, 2003; Chaine and Lyon, 2008). Other principal components were not retained as their eigenvalue was less than 1 (Quinn \& Keough 2002). Mass corrected for body size, a measure sometimes linked to condition (Brown 1996), was calculated as the residual of mass regressed on this body size principal component. The color data were processed using ColoR 1.7 software (Montgomerie 2006) and we used total brightness (total \% reflectance from 300 to $700 \mathrm{~nm}$ ) of each crown feature as the measure of color, since it showed the most variation among individuals in our study population. The gold patch showed little variation among individuals in overall hue, UV peak hue or red saturation, which are traditionally studied for carotenoid-based traits (Montgomerie 2006), so we focused only on total brightness rather than these other measures. We then averaged the three brightness measures for each plumage trait to obtain a single measure (repeatability of readings taken 1 month apart: black: $r_{2,62}=0.65 \pm 0.07$; gold: $\left.r_{2,62}=0.52 \pm 0.09\right)$.

Tests of the influence of plumage on social dominance should involve birds not previously familiar with each other; otherwise prior interactions could confound the influence of status signals. Therefore, our three sites for capturing experimental birds were over $0.5 \mathrm{~km}$ apart, further than the home range size of individual birds (Price 1931; B. E. Lyon, D. Shizuka, \& A. S. Chaine, unpublished data) and all dominance trials involved dyads of individuals from two different sites. After the dominance trials were completed, all birds were released at their respective capture sites.

\section{DNA-based Sexing}

We used sex-linked molecular markers (CHD-W/Z primers, Griffiths et al. 1998) to determine the sex of each bird used in dominance trials. We verified that this method is accurate for identifying males and females using tissue from specimens at the UC Berkeley Museum of Vertebrate Zoology that were sexed during dissection ( $N=11$ males, 8 females). Amplified PCR products were run on $3 \%$ NuSieve agarose gels, run at 80-90 V for 2-3 h, stained in SYBR Gold, and visualized under UV light to score sex based on the presence or absence of a Wspecific fragment.

\section{Experimental Dominance Trials}

After measurement, each bird was transferred to an outdoor housing aviary with up to three other individuals captured on 
the same day from the same location and flock (i.e. familiar birds were housed together). We had two holding aviaries to hold individuals from separate populations, and these aviaries were placed out of visual and acoustic contact from each other at the University of California Santa Cruz Arboretum. Each aviary measured $1.2 \mathrm{~m}$ on each side, was covered with a plywood sheet to provide shelter from direct sunlight and precipitation, and contained perches and shelter. Birds were provided with millet seed and water ad libitum with as many feeding trays as there were birds to ensure that all birds could easily get access to food and to reduce aggression during the pretrial period (Pryke et al. 2002). All birds were allowed to acclimate to their respective housing aviaries without disturbance for 1-3 days before being observed in the dominance trials.

We conducted 30 paired dominance trials to assess the influence of plumage patch size and color on social dominance. Birds paired in a given dominance trial were selected at random based on band number the evening before a trial from the set captured on the same day to ensure that both birds had been in captivity for the same duration. Random selection of participants in a trial should have eliminated any bias of results caused by the effects of prior experience in the holding cages or in their natural populations prior to capture. All trials were conducted in the morning (0800-1100 hours) with no fasting period prior to the trial, which should reduce dominance asymmetries caused by differences in motivation linked to hunger level. The experimental aviary had the same dimensions as the housing aviaries, but to encourage interactions contained only a single water and food dish located centrally and surrounded by a small cluster of branches for perching. Birds were caught in their housing cages with a small sweep net and the two birds were captured immediately one after the other (ca. $1 \mathrm{~min}$ apart). Individuals were released simultaneously from a two-chambered box after a short period of time in this box (ca. $2 \mathrm{~min}$ ) and were observed with binoculars for $30 \mathrm{~min}$ from a $20 \mathrm{~m}$ distance. Birds showed the same behaviors we observe in the field and we observed no signs of stress within $1 \mathrm{~min}$ of their release from the two-chambered box.

We scored the outcome of two types of behavioral interactions that reflect social dominance: aggression and avoidance (Watt 1986a). Aggressive behavior was defined as the initiation of fighting, chasing or lunging directed at the second bird. The bird initiating an aggressive interaction always gained access to the food dish when they were near the feeder (many interactions occurred away from the feeder). Actual physical contact was extremely rare and no birds showed any signs of injury as a result of the experiment. Avoidance interactions were scored when an individual failed to challenge the other bird for access to food or a perch; avoidance typically entailed the subordinate perching away from the resource but not approaching it, as has been observed in other studies (Watt 1986a). In most cases of avoidance interactions, the subordinate bird approached the food or perch only after the dominant individual vacated the resource, as we observe for interactions in the wild (B. E. Lyon, D. Shizuka \& A. S. Chaine, unpublished data). During a given trial, both aggressive and avoidance behaviors could be observed, although aggression was rarely seen in the first $10 \mathrm{~min}$ of the trial. We assigned dominance status (dominant or subordinate) to the two birds in a trial based on which bird was dominant in the majority of behavioral interactions within a trial (i.e. which bird supplanted the other and was avoided). The dominance outcome of the interaction trials was extremely consistent: only one of 10 trials with overt aggression showed any reversals in behaviors associated with dominance (i.e. the subordinate won $1 / 3$ supplant interactions in that trial) during the trial, and only one of 20 trials with avoidance behavior showed a reversal in dominance behaviors (i.e. the subordinate won $1 / 4$ avoidance interactions in that trial) during the trial. In eight trials, neither direct behavioral interactions (i.e. no interactions at all) nor a difference in access to food allowed us to distinguish dominance, and so we did not assign individuals from these trials a dominance category, but rather they were scored as 'tolerant' for the analysis of escalation in aggression. No bird was used in more than one dominance trial. All methods were approved by the UCSC IACUC and complied with Federal and California State banding permits.

\section{Statistical Analyses}

We performed separate, simple correlations to examine associations among traits using all birds captured in 2005 and 2006 (i.e. we limited the analysis to the same years in which the experiments were done; results in Table 1). We conducted separate analyses for aggressive and avoidance interactions as these could reflect different levels of dominance escalation. Clear evidence for multiple signals would come from demonstrating that different levels of dominance escalation are predicted by different signals. We used paired $t$ tests to assess the importance of relative plumage attributes and body size in determining the outcome of interactions between pairs of birds. To determine whether aggressive escalation (i.e. no escalation versus trials with some overt aggression) was predicted by the magnitude of the differences between individuals in body size or plumage traits, we used a generalized linear regression model with a logit link function. We first constructed a full model including the relative difference between individuals in each trait (plumage and morphological) as predictor variables along with their interaction terms as independent variables and the presence or absence of aggression as the binary response variable. We then removed individual variables and used likelihood ratio tests to determine the possible effect of particular traits on the presence or absence of aggression. Since there were no significant interactions between traits in their effect on escalation, we compared reduced models to a model with all single variables but without interaction terms. Traits were normally distributed or transformed to achieve normality (square-root-transformed gold crown size and log-transformed black crown size) as determined by visual inspection of probability plots prior to tests. Data conform to the assumptions of parametric statistical tests, which were confirmed for each analysis. Statistical tests were completed using SYSTAT (SPSS Inc., Chicago, IL, U.S.A.) or R software (R Development Core Team 2009) using a two-tailed critical value. Standardized effect sizes (Fisher's $Z r \pm \mathrm{SE}$ ) were calculated from test statistics of the statistical models following Nakagawa \& Cuthill (2007).

\section{Results}

Among the six traits studied, and 15 different possible pairwise trait correlations, we detected six significant correlations (Table 1). The size of an individual's black crown patch was correlated with both how dark that patch was and the size of

Table 1. Pearson correlation coefficients for pairs of morphological and plumage traits of golden-crowned sparrows for all birds captured in the winters of 2005 and 2006

\begin{tabular}{lccccc}
\hline & $\begin{array}{l}\text { Body } \\
\text { size }\end{array}$ & $\begin{array}{l}\text { Residual } \\
\text { mass }\end{array}$ & $\begin{array}{l}\text { Black } \\
\text { size }\end{array}$ & $\begin{array}{l}\text { Gold } \\
\text { size }\end{array}$ & $\begin{array}{l}\text { Black } \\
\text { color }\end{array}$ \\
\hline Body size & - & & & & \\
Residual mass & 0.01 & - & & & \\
Black size & $0.29^{* * *}$ & 0.11 & - & & \\
Gold size & $0.24^{* * *}$ & 0.13 & $0.28^{* * *}$ & - & \\
Black color & $-0.19^{*}$ & $-0.22^{* *}$ & $-0.29^{* * *}$ & -0.01 & - \\
Gold color & 0.03 & 0.01 & 0.01 & 0.05 & -0.05 \\
\hline
\end{tabular}

$d f=204$ for color patch size and body size and 164 for patch color. ${ }^{*} P<0.05$; ${ }^{* *} P<0.01$; ${ }^{* * *} P<0.001$. 

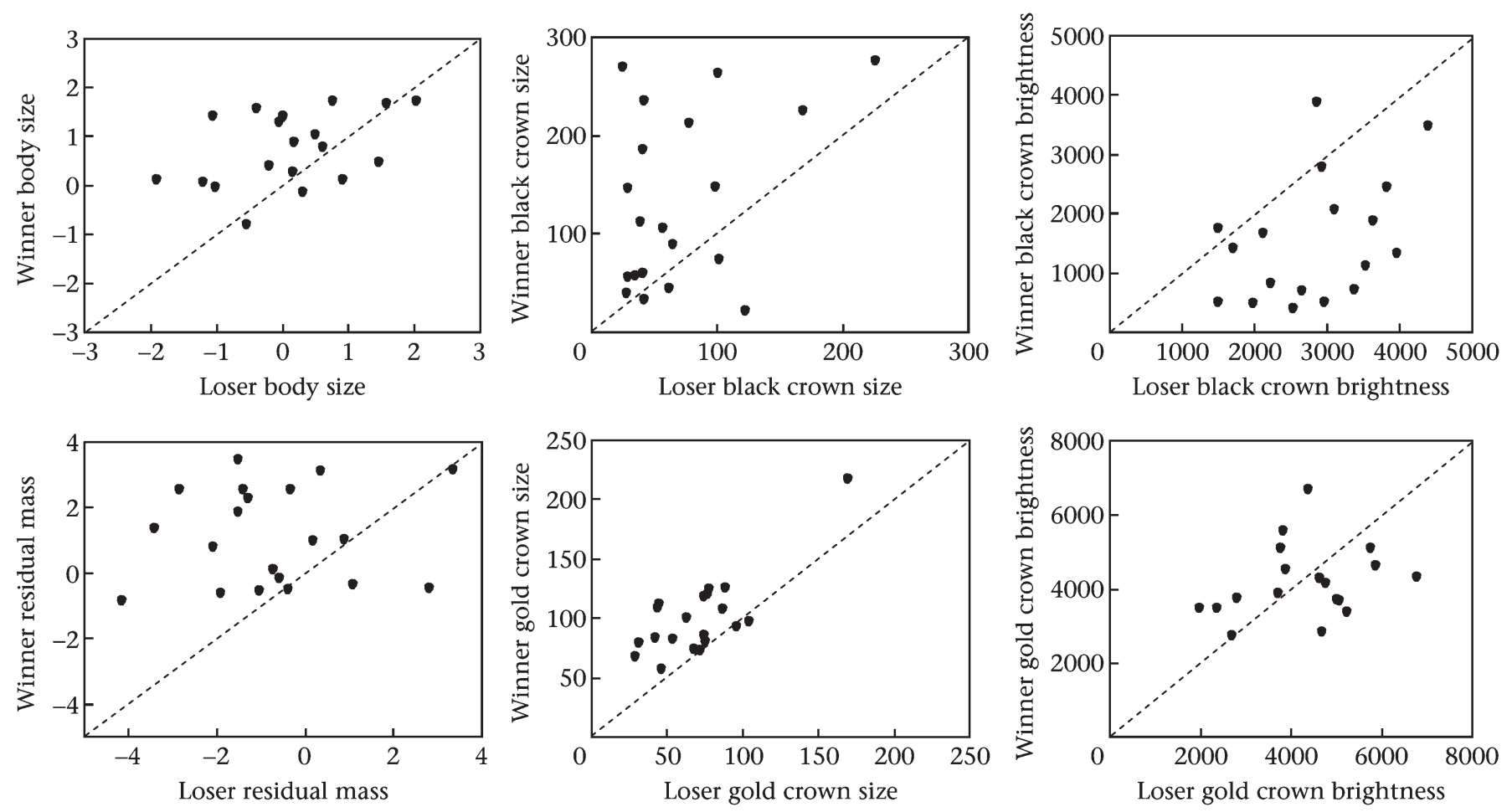

Figure 1. Comparison of traits of winners relative to losers in paired experimental dominance trials that did not escalate beyond avoidance interactions. Points offset well above or below the 1:1 line indicate dyads where the winner and loser differed substantially in the trait of focus. Crown size is measured in $\mathrm{mm}^{2}$, crown color as total \% brightness between 320 and $700 \mathrm{~nm}$ (lower black brightness indicates a darker crown), and morphological traits are standardized trait values (scaled to mean).

its gold crown patch. Body size, which could be important in determining dominance, was associated with the sizes of both the gold and black crown patches and to a lesser degree the darkness of the black patch. Residual mass was somewhat correlated with the darkness of the black patch. In all cases, however, associations among traits were fairly weak $(r<0.3)$ suggesting that the different traits could provide somewhat independent information from each other.

By chance, half of all trials where sex was determined $(12 / 25)$ involved mixed-sex dyads (one male, one female). This allowed us to assess whether sex influenced social dominance. Sex was not significantly associated with social dominance and females were as likely to be dominant over males as vice versa in dyads with mixed-sex pairs (5/12 trials; sign test: $P=0.77$ ). In mixed-sex trials, males and females showed no difference in the number of aggressive or avoidance behaviors during the trial (paired $t$ test: aggression: $t_{12}=0.94, P=0.37$; mean difference $\pm \mathrm{SE}=0.3 \pm 1.2$; avoidance: $t_{12}=1.51, P=0.16$; mean difference $\pm \mathrm{SE}=1.7 \pm 3.8$ ). Among same-sex trials, there was no difference in the number of aggressive and avoidance behaviors between male-only and female-only trials (ANOVA: aggression: $F_{1,11}=3.16, P=0.10$; mean \pm SE: female only: $1.2 \pm 2.0$; male only: $6.0 \pm 1.9$; avoidance: $F_{1,11}=1.55, P=0.24$; mean \pm SE: female only: $1.0 \pm 1.0$; male only: $2.7 \pm 0.9$ ). Trials with same-sex dyads had a higher number of aggression behaviors than trials with different sexes (ANOVA: aggression: $F_{1,23}=4.34, P=0.049$; mean \pm SE: same sex: $3.8 \pm 1.1$; mixed sex: $0.5 \pm 1.1$ ) but a similar number of avoidance behaviors (ANOVA: avoidance: $F_{1,23}=1.02, P=0.32$; mean \pm SE: same sex: $1.9 \pm 0.7$; mixed sex: $3.0 \pm 0.8$ ). For all subsequent analysis, data were pooled with respect to sex.

We analyzed avoidance interactions and aggressive interactions separately to determine whether dominance in the two contexts was associated with different plumage features. In the subset of trials in which avoidance interactions occurred $(N=20)$, dominant individuals were larger than subordinates and had higher residual mass (Figure 1, Table 2). Dominant individuals in these dyads also had black crown patches that were both larger and darker than those of the subordinate individual of the dyads (Figure 1, Table 2). Finally, the gold crown patches of dominant individuals were larger but did not differ in brightness compared to gold crowns of the corresponding subordinate individuals (Figure 1, Table 2). When we restricted our analysis to trials that contained only avoidance behaviors (i.e. excluding trials with both avoidance and aggression), the same trait comparisons were significant and effect sizes were similar despite lower sample sizes $(N=12)$.

Focusing on interactions in which overt aggression occurred $(N=10)$, we found that dominant individuals had significantly darker black crown patches than the corresponding subordinates (Figure 2, Table 2). However, there was no difference between dominants and subordinates in body size, residual mass, black crown size, gold crown size or brightness of gold plumage (Figure 2, Table 2).

Of the 27 trials in which we had all trait measurements, nine escalated to overt aggressive interactions whereas the remaining 18 trials showed much lower levels of conflict,

Table 2. Statistics of paired $t$ tests comparing the traits of dominant and subordinate individuals in a trial for both trials that included avoidance behavior and those that included overt aggression behavior

\begin{tabular}{lccrlrrrr}
\hline & \multicolumn{3}{l}{ Avoidance } & & \multicolumn{3}{c}{ Aggression } \\
\cline { 2 - 3 } \cline { 6 - 8 } & $N$ & $P$ & Effect size $^{*}$ & & $N$ & $P$ & Effect size \\
\hline Body size & 20 & 0.007 & $0.63 \pm 0.24$ & & 10 & 0.51 & $0.22 \pm 0.38$ \\
Residual mass & 20 & 0.002 & $0.74 \pm 0.24$ & & 10 & 0.17 & $0.45 \pm 0.38$ \\
Black crown size & 20 & 0.004 & $0.60 \pm 0.24$ & & 10 & 0.50 & $-0.03 \pm 0.38$ \\
Gold crown size & 20 & $<0.001$ & $1.07 \pm 0.24$ & & 10 & 0.12 & $0.51 \pm 0.38$ \\
Black color & 18 & $<0.001$ & $-1.02 \pm 0.26$ & & 9 & 0.04 & $-0.74 \pm 0.41$ \\
Gold color & 18 & 0.73 & $-0.08 \pm 0.26$ & & 9 & 0.66 & $0.15 \pm 0.41$ \\
\hline
\end{tabular}

* Fisher-corrected effect sizes \pm SE. 

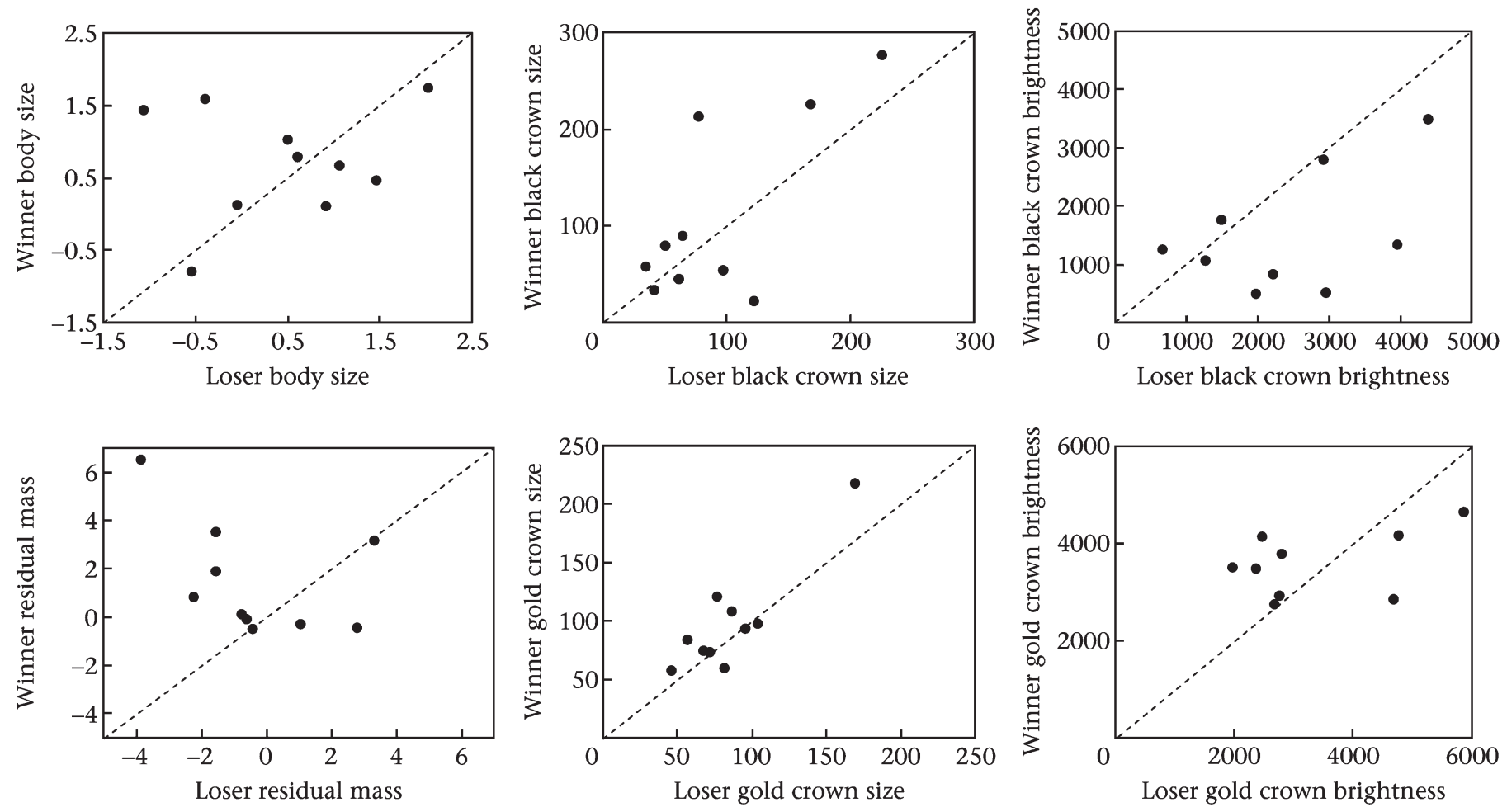

Figure 2. Comparison of traits of winners relative to losers in paired experimental dominance trials where aggressive interactions determined dominance. Points above the 1:1 line indicate that the winner had a larger trait value than the loser. Crown size is measured in mm², $\mathrm{crown}^{\mathrm{c}} \mathrm{color}$ as total \% brightness between 320 and $700 \mathrm{~nm}$ (lower black brightness indicates a darker crown), and morphological traits are standardized trait values (scaled to mean).

including either avoidance interactions $(N=11)$ or little direct behavioral interaction and no clear dominance (e.g. tolerance; $N=7$ ). To determine whether plumage or body size signals play a role in preventing escalation, we compared the traits of participants in trials that escalated to overt aggression to those that did not. Similarity in gold patch size among birds in a dyad was the only significant predictor of whether interactions escalated to aggression (GLM: log-likelihood $=-3.27$,

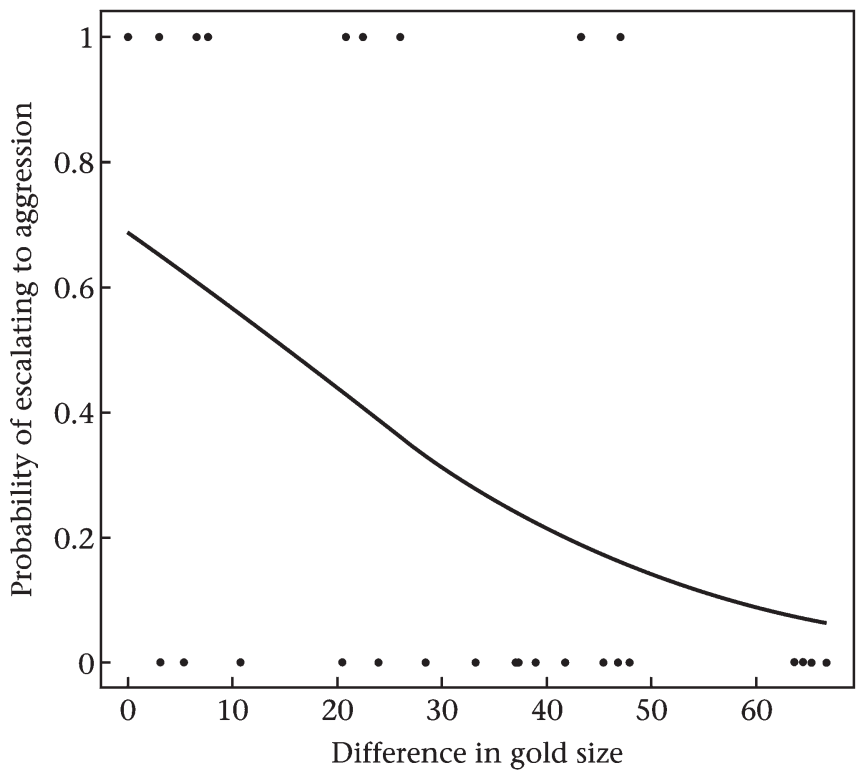

Figure 3 . The probability that a dyadic interaction escalated to aggression rather than being settled by other means (i.e. avoidance or tolerance) as a function of difference in gold patch sizes $\left(\mathrm{mm}^{2}\right)$ between the two contestants.
$P=0.01$; Figure 3 ): dyads involving individuals with differently sized gold patches were less likely to escalate to aggression than those with individuals whose gold crown patches were similar in size. None of the other traits we measured predicted whether or not aggressive interactions occurred: black patch size (log-likelihood $=-0.85, P=0.19)$; black patch color (log-likelihood $=-0.12, P=0.62)$; gold patch color (log-likelihood $=-0.27, P=0.46$ ); body size (log-likelihood $=-0.09$, $P=0.68)$; and residual mass (log-likelihood $=-1.08, P=0.14$ ).

\section{Discussion}

Our study makes three contributions to understanding winter signals of social dominance. First, we showed that plumage characteristics in golden-crowned sparrows function as status signals in contests during winter. Second, our experiments revealed that these status signals can function in the absence of prior experience between the interacting individuals because our experiments involved birds from geographically separated flocks with no previous social experience with each other. Similarly, our results show that the status signals are independent of any residency effects because the contests over resources were conducted in neutral aviaries away from the home ranges of the birds. Third, and most novel, our study provides evidence that golden-crowned sparrows may use multiple status signals during the winter; different plumage traits are used in different contexts of social dominance that together seem to provide a sophisticated graded response.

Plumage-based status signals have been documented in a wide variety of birds, mostly in a nonbreeding context but also in the context of sexual selection (reviewed in Senar, 1999, 2006). Our observations align closely with the predictions and assumptions of status signaling theory (Rohwer, 1975; Whitfield, 1987; Searcy and Nowicki, 2005); most sparrows in our experiment were able to establish social dominance without any aggression whatsoever, while a few escalated to low lev- 
els of overt aggression (supplants, chases), and interactions involving risky physical contact were extremely rare. Moreover, the birds established social dominance despite lacking previous experience with each other, and hence had no information about fighting ability. This context (encounters between birds unfamiliar with each other) is precisely the context Rohwer (Rohwer, 1975, 1982; Rohwer and Ewald, 1981) felt was conducive to the evolution of status signals.

In many species, males are socially dominant over females, probably because body size is an important determinant of social dominance and males tend to be larger than females (Geist, 1966; Andersson, 1980; Kodric-Brown and Brown, 1984). However, in our mixed-sex trials, female golden-crowned sparrows were as likely to be dominant over males as vice versa, despite some sexual dimorphism in size and crown features (Norment et al. 1998; B. E. Lyon, D. Shizuka, \& A. S. Chaine, unpublished data). Demonstrating that status signals function independently of sex is noteworthy given the early vigorous debate over whether badges of status were simply signals of sex or age (Balph et al., 1979; Rohwer, 1982; Watt, 1986b; Whitfield, 1987; Senar, 2006). This issue was thought important in terms of the mechanism of honesty that could prevent cheating on a signal, which in part was tied up with the definition of badges of status (Searcy \& Nowicki 2005). Specifically, since life history tradeoffs can easily explain the stability of sex- and age-dependent signals, there was interest in demonstrating whether signals could work within age and sex classes. Many previous studies, however, were unable to demonstrate that status signals play a role in establishing dominance within sex or age classes (e.g. Rohwer, 1977; Parsons and Baptista, 1980; Fugle et al., 1984; Watt, 1986b; Jackson et al., 1988; Piper and Wiley, 1989; Kopachena and Falls, 1993). These issues are somewhat less relevant, at least for golden-crowned sparrows, given our demonstration that status signals can function between the sexes. While sex did not determine dominance in same-sex trials, we did find a higher level of overt aggression in within-sex than between-sex trials. Regardless, we agree with Searcy \& Nowicki (2005) that the important question is to understand both the context in which the signals are used and the underlying mechanisms that allow for a stable signaling system that contains at least some reliable information. Finding that life history trade-offs explain the stability of signaling systems in some species, as would be the case if signals exclusively signaled age or sex, is not less interesting than other explanations for signal stability.

Our most important contribution is evidence that different plumage patches may function as independent, or 'multiple', badges of status in a winter social context. There is now abundant evidence that complex plumage coloration in birds functions as multiple signals, but most of this work has focused on a mate choice context (Candolin 2003). The use of multiple signals in an agressive context is far less studied, and even here, most studies involve aggression in the context of sexual selection (e.g. Järvi and Bakken, 1984; Ligon et al., 1990; Chaine and Lyon, 2008). To our knowledge, our study is only the third to examine and provide evidence that birds use multiple signals to establish social dominance in winter (Balph et al., 1979; Bókony et al., 2006). Our results are likely to reflect a general pattern of multiple status signal use in winter, since the few studies that have actually searched for this pattern have found evidence for it, and also because there is no basis for assuming that multiple signals should be restricted to sexual selection.

We were successful in demonstrating multiple signals for two reasons: we examined several different plumage traits, but more importantly, we examined the connection of these plumage traits to two different contexts by which social dominance is established: avoidance and aggression. In a large pro- portion of trials, dominance was clear because one individual avoided the other, and it is clear that some signaling mechanism rather than overt conflict was used to resolve dominance relationships. Several plumage traits are likely candidates for the signals used to establish relative dominance without aggression: the size and color of the black patch and the size of the gold patch. These traits are at best weakly correlated $(r<0.3)$ with each other, which suggests that each trait has plenty of scope for providing independent information about fighting ability. Although three different plumage traits were associated with dominance in these trials, one trait in particular appeared to play a disproportionate role in preventing escalation to more aggressive interactions. Trials in which the size of the gold crown patch was similar in the two birds were more likely to escalate to aggressive behaviors such as supplanting and chasing than were trials where the birds differed substantially in the size of the gold patch. The differences in size of the black crown patch, however, did not affect whether trials escalated to aggression, but were a predictor of the eventual outcome of the contest, whether it was resolved by aggression or avoidance. Gold and black plumage patches seem to affect both the pattern and outcome of social interactions in golden-crowned sparrows, but their precise functions appear to be somewhat independent.

Our experiment did not involve signal manipulations so it is tricky to distinguish between cause and correlation when interpreting our plumage patterns, particularly because some of the plumage traits show moderate correlations with each other, and with body size. However, the effect sizes of plumage and body size traits within an analysis allow us some insight into the relative importance of the different traits for dominance encounters in the trials. In nearly all cases, the effect of a plumage trait (size or color) was greater than the effect of body size or residual body mass, suggesting that plumage patches provide information about social dominance above and beyond the simple effects that body size has on social status. In other words, if body size explains part of the link between color patch size and social status, it cannot explain the entire pattern. Indeed, gold patch color, not body size, was the only trait that predicted the probability of escalation in a trial. Furthermore, the two traits that best predicted dominance in nonaggressive contests, gold patch size and black patch color, had roughly similar effect sizes but were not correlated with each other, suggesting these two traits function independently. Indeed, these two color traits originate from different physiological mechanisms, carotenoid- versus melanin-based pigment systems, and therefore are likely to convey different types of information about the signal bearer (Hill 2006). While the results we present here show that multiple status signals are used to establish dominance, experimental manipulations of crown patches will be necessary to confirm that it is the crown patches themselves that signal dominance and not some other unmeasured trait that is linked to body size and crown patch features.

Taken together, our experiment reveals that the multiple signals may provide a graded signaling system that could enable unfamiliar birds to establish dominance with minimal aggression and virtually no physical violence. A similar result was found in a study of multiple status signals in breeding lark buntings, Calamospiza melanocorys. Male buntings display a number of traits associated with social dominance, and some traits are more important at long distances while others primarily function at close range in escalated conflicts (Chaine \& Lyon 2008). Context-dependent use of status signals in contests that can vary in escalation remains underappreciated ( Andersson, 1980; Enquist et al., 1990; Chaine and Lyon, 2008), yet it may turn out to be a general explanation for multiple status signals in both breeding and nonbreeding contexts. 
Acknowledgments - Comments by Valentin Amrhein and two anonymous referees for Animal Behaviour substantially improved the manuscript. Special thanks to the UCSC Arboretum and Stephen McCabe for generously providing us with space for our aviaries and logistic support. The UC Berkeley Museum of Vertebrate Zoology and Carla Cicero kindly provided us with tissue samples to verify the molecular sexing probes. UCSC MEEG and John Thompson kindly provided us with molecular facilities. This work was funded by a UCSC special research grant and National Geographic Society grant to B.E.L. and NSF-DDIG (IBN-0309215) grant to A.S.C. and B.E.L.

\section{References}

Andersson, M. 1980. Why are there so many threat displays? Journal of Theoretical Biology, 86, 773-781.

Andersson, S., \& Prager, M. 2006. Quantification of coloration. In Bird Coloration 1: Mechanisms and Measurements (ed. G. Hill \& K. McGraw), pp. 41-89. Cambridge: Harvard University Press.

Balph, M. H., Balph, D. F., \& Romesburg, H. C. 1979. Social status signaling in winter flocking birds: An examination of a current hypothesis. Auk, 96, 78-93.

Bókony, V., Lendvai, A. Z., \& Liker, A. 2006. Multiple cues in status signalling: The role of wingbars in aggressive interactions of male house sparrows. Ethology, 112, 947-954.

Brown, M. E. 1996. Assessing body condition in birds. In Current Ornithology (ed. V. Nolan \& E. D. Ketterson), pp. 67-135. New York: Plenum.

Candolin, U. 2003. The use of multiple cues in mate choice. Biological Reviews, 78, 575-595.

Chaine, A. S., \& Lyon, B. E. 2008. Intrasexual selection on multiple plumage ornaments in the lark bunting. Animal Behaviour, 76, 657-667.

Enquist, M., Leimar, O., Ljungberg, T., Mallner, Y., \& Segerdahl, N. 1990. A test of the sequential assessment game: Fighting in the cichlid fish Nannacara anomala. Animal Behaviour, 40, 1-14.

Fugle, G. N., Rothstein, S. I., Osenberg, C. W., \& McGinley, M. A. 1984. Signals of status in wintering white-crowned sparrows, Zonotrichia leucophrys gambelii. Animal Behaviour, 32, 86-93.

Geist, V. 1966. The evolution of horn-like organs. Behaviour, 27, 175-214.

Griffiths, R., Double, M., Orr, K., \& Dawson, R. 1998. A DNA test to sex most birds. Molecular Ecology, 7, 1071-1075.

Hill, G. E. 1992. An inexpensive source of colored leg bands. Journal of Field Ornithology, 63, 408-410.

Hill, G. E. 2006. Female mate choice for ornamental coloration. In Bird Coloration: Functions and Evolution (ed. G. E. Hill \& K. J. McGraw), pp. 137-200. Cambridge: Harvard University Press.

Hill, G. E., \& Montgomerie, R. 1994. Plumage colour signals nutritional condition in the house finch. Proceedings of the Royal Society B, 258, 47-52.

Jackson, W. M., Rohwer, S., \& Winnegrad, R. L. 1988. Status signaling is absent within age-and-sex classes of Harris' sparrows. Auk, 105, 424-427.

Järvi, T., \& Bakken, M. 1984. The function of the variation in the breast stripe of the great tit (Parus major). Animal Behaviour, 32, 590-596.

Jawor, J. M., \& Breitwisch, R. 2003. Melanin ornaments, honesty, and sexual selection. Auk, 120, 249-265.

Kodric-Brown, A., \& Brown, J. H. 1984. Truth in advertising the kinds of traits favored by sexual selection. American Naturalist, 124, 309-323.

Kopachena, J. G., \& Falls, J. B. 1993. Aggressive performance as a behavioural correlate of plumage polymorphism in the white-throated sparrow (Zonotrichia albicollis). Behaviour, 124, 249-266.

Ligon, J. D., Thornhill, R., Zuk, M., \& Johnson, K. 1990. Male-male competition ornamentation and the role of testosterone in sexual selection in red jungle fowl. Animal Behaviour, 40, 367-373.

MacDougall-Shackleton, E. A., Stewart, K. A., Potvin, D. A., \& Tennenhouse, E. 2009. The rich get richer: Song complexity predicts song element sharing and song output in song sparrows Melospiza melodia. Animal Behaviour, 78, 141-146.

McGraw, K. J. 2003. Melanins, metals, and mate quality. Oikos, 102, 402-406.

McGraw, K. J. 2006a. The mechanics of carotenoid coloration in birds. In Bird Coloration 1: Mechanisms and Measurements (ed. G. Hill \& K. McGraw), pp. 177-242. Cambridge: Harvard University Press.

McGraw, K. J. 2006b. Mechanics of melanin-based coloration. In Bird coloration 1: Mechanisms and Measurements (ed. G. Hill \& K. McGraw), pp. 243-294. Cambridge: Harvard University Press.

McGraw, K. J., Hudon, J., Hill, G. E., \& Parker, R. S. 2005. A simple and inexpensive chemical test for behavioural ecologists to determine the presence of carotenoid pigments in animal tissues. Behavioral Ecology and Sociobiology, 57, 391-397.

Møller, A. P., \& Pomiankowski, A. 1993. Why have birds got multiple sexual ornaments? Behavioral Ecology and Sociobiology, 32, 167-176.

Montgomerie, R. 2006. Analyzing the colors of birds. In Bird Coloration: Mechanisms and Measurements (ed. G. Hill \& K. McGraw), pp. 90-147. Cambridge: Harvard University Press.

Nakagawa, S., \& Cuthill, I. C. 2007. Effect size, confidence interval and statistical significance: A practical guide for biologists. Biological Reviews, $82,591-605$.

Norment, C. J., Hendricks, P., \& Santonocito, R. 1998. Golden-crowned sparrows (Zonotrichia atricapilla). In The Birds of North America (ed. A. Poole \& F. Gill). Philadelphia: The Academy of Natural Sciences/ Washington, DC: The American Ornithologists' Union

Parsons, J., \& Baptista, L. F. 1980. Crown color and dominance in the whitecrowned sparrow. Auk, 97, 807-815.

Pearson, O. P. 1979. Spacing and orientation among feeding goldencrowned sparrows. Condor, 81, 278-285.

Piper, W. H., \& Wiley, R. H. 1989. Correlates of dominance in wintering white-throated sparrows: age, sex and location. Animal Behaviour, 37, 298-310.

Price, J. B. 1931. Some flocking habits of the crowned sparrows. Condor, 33, 238-242.

Pryke, S. R., \& Andersson, S. 2003. Carotenoid-based epaulettes reveal male competitive ability: Experiments with resident and floater redshouldered widowbirds. Animal Behaviour, 66, 217-224.

Pryke, S. R., Andersson, S., Lawes, M. J. \& Piper, S. E. 2002. Carotenoid status signaling in captive and wild red-collared widowbirds: Independent effects of badge size and color. Behavioral Ecology, 13, 622-631.

Quinn, G. D., \& Keough, M. J. 2002. Experimental Design and Data Analysis for Biologists. Cambridge: Cambridge University Press.

R Development Core Team 2009. R: A Language and Environment for Statistical Computing. Vienna: R Foundation for Statistical Computing.

Rohwer, S. A. 1975. The social significance of avian winter plumage variability. Evolution, 29, 593-610.

Rohwer, S. 1977. Status signaling in Harris sparrows: Some experiments in deception. Behaviour, 61, 107-129.

Rohwer, S. 1982. The evolution of reliable and unreliable badges of fighting ability. American Zoologist, 22, 531-546.

Rohwer, S., \& Ewald, P. W. 1981. The cost of dominance and advantage of subordination in a badge signaling system. Evolution, 35, 441-454.

Rohwer, S. 1985. Dyed birds achieve higher social status than controls in Harris' sparrows Zonotrichia querula. Animal Behaviour, 33, 1325-1331.

Searcy, W. A., \& Nowicki, S. 2005. The Evolution of Animal Communication: Reliability and Deception in Signaling Systems. Princeton, New Jersey: Princeton University Press.

Senar, J. C. 1999. Plumage coloration as a signal of social status. In Proceedings of the International Ornithological Congress (ed. N. Adams \& R. Slotow), pp. 1669-1689. Durban: BirdLife International.

Senar, J. C. 2006. Color displays as intrasexual signals of aggression and dominance. In Bird Coloration 2: Function and Evolution (ed. G. Hill \& K. McGraw), pp. 87-136. Cambridge: Harvard University Press.

Sprau, P., Roth, T., Schmidt, R., Amrhein, V., \& Naguib, M. 2010. Communication across territory boundaries: Distance-dependent responses in nightingales. Behavioral Ecology, 21, 1011-1017.

Stuart-Fox, D. M., Firth, D., Moussalli, A., \& Whiting, M. J. 2006. Multiple signals in chameleon contests: designing and analysing animal contests as a tournament. Animal Behaviour, 71, 1263-1271.

Tibbetts, E. A., \& Safran, R. J. 2009. Co-evolution of plumage characteristics and winter sociality in New and Old World sparrows. Journal of Evolutionary Biology, 22, 2376-2386.

Watt, D. J. 1986a. A comparative study of status signaling in sparrows (genus Zonotrichia). Animal Behaviour, 34, 1-15.

Watt, D. J. 1986b. Relationship of plumage variability, size and sex to social dominance in Harris' sparrows. Animal Behaviour, 34, 16-27.

Whitfield, D. P. 1987. Plumage variability, status signalling, and individual recognition in avian flocks. Trends in Ecology \& Evolution, 2, 13-18.

Whitfield, D. P. 1988. The social significance of plumage variability in wintering turnstone Arenaria interpres. Animal Behaviour, 36, 408-415.

Whiting, M. J., Nagy, K. A., \& Bateman, P. W. 2003. Evolution and maintenance of social status signalling badges: experimental manipulations in lizards. In Lizard Social Behavior (ed. S. F. Fox, J. K. McCoy, \& T. A. Baird), pp. 47-82. Baltimore: Johns Hopkins University Press.

Zucker, N. 1994. A dual status-signalling system: A matter of redundancy or differing roles? Animal Behaviour, 47, 15-22. 